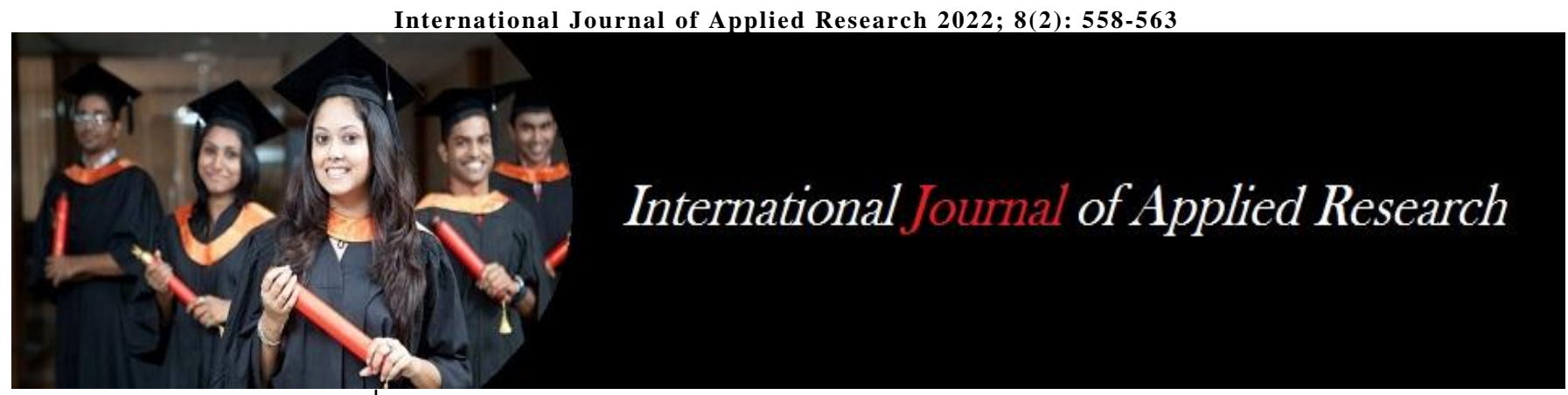

ISSN Print: 2394-7500 ISSN Online: 2394-5869 Impact Factor: 8.4 IJAR 2022; 8(2): 558-563 www.allresearchjournal.com Received: 10-12-2021 Accepted: 15-01-2022

Dr. Amulya Kumar Acharya Associate Professor, P.G. Department of Education, Fakir Mohan University, Balasore, Odisha, India
Corresponding Author: Dr. Amulya Kumar Acharya Associate Professor, P.G. Department of Education, Fakir Mohan University, Balasore, Odisha, India

\section{Social adjustment of tribal girls of aspirational districts of Odisha in relation to their socio-economic status}

\section{Dr. Amulya Kumar Acharya}

DOI: https://doi.org/10.22271/allresearch.2022.v8.i2h.9500

\begin{abstract}
Success of an individual is largely depends upon the way which he/she interact with other individuals of the society. Social adjustment is the key for leading happy and fruitful life. Social adjustable persons lead a quality life. The ultimate aim of education is to bring about socially acceptable thinking and well desired response to the society. The present study was aimed to find the social adjustment of tribal girls of aspirational districts of Odisha in relation to their socio-economic status. The objectives of the study were a. To study the social adjustment of tribal girls of aspirational districts of Odisha, b. To compare the social adjustment of tribal girls in relation to the locality, c. To study the socio-economic status of the Parent's of the tribal girls of aspirational districts of Odisha, d. To compare the mean score of social adjustment of tribal girls of low, medium and high socio-economic status of their parents., e. To find the relationship between social adjustment of adolescent tribal girls and their Parent's socio-economic status. The investigator adopted descriptive survey method for the present study. All secondary school students belonging to aspirational districts of Odisha was considered as Population of the study. So, all the students of secondary school, studying in class IX and X in the Malkangiri, Nuapada, Balangir, Kalahandi, Kandhamal, Gajapati, Dhenkanal, Koraput, Rayagada, Nawarangapur district are population for the Present study. From above mentioned population researcher randomly selected 316 tribal girls as the sample of the study. Social Adjustment Scale by Dr. Ashutosh Kumar has been adopted for data collection of the study. Socio-economic status scale developed and standardized by Rajeev Lochan Bharadwaj, translated \& standardized by Dr Amulya Kumar Acharya was adopted for data collection of the study. The results of the study found that most of the tribal girls have average level of social adjustment, Urban tribal girls have better social adjustment that rural tribal girls, most of the parents have low socio-economic status, the social adjustment of tribal girls belonging to high, medium and low socio-economic status differs significantly, and social adjustment and socio-economic status were positive and significantly correlated.
\end{abstract}

Keywords: Social adjustment, socio-economic status, tribal girls, aspirational district

\section{Introduction}

"Education for all" is the building block of national development. India had taken a pledge through its constitution that within a period of eight years, free and compulsory elementary education would be provided to all children up to the age of 14 years. Schools are established everywhere across the land. Various measures were adopted to bring all children to school irrespective of class, caste and gender barriers. However, even after decades, the goal of Universalization of Elementary Education remains unachieved.

Education is to bring happiness within and outside of an individual. It can be defined as the instrument for developing the best in human being. The aim of educational system is to facilitate wings for all round development of learners. It helps one to attain intellectual, physical, spiritual, social and emotional development. But life is a continuous process of adjustment. Adjustment is the process by which living organism maintains a balance between its need and the circumstances that influence the satisfaction of these needs (Shaffer, 1961) ${ }^{[13]}$. Psychology can be defined as the science of human behavior, and behavior can be better understood if we know the process of adjustment. In fact, people by making adjustment to the different spheres of life, try to cope or solve the problems of everyday life (Goodstein \& Lanyon, 1975) ${ }^{[5]}$. Some persons are well adjusted and some are less adjusted (Jain \& Yadav, 2019) ${ }^{[6]}$. 
Among various types of adjustment, psychologists have considered five major types of adjustments such as home, health, social, emotional and school which is the most important aspect of harmonious development.

Social adjustment can be defined as a psychological process. It frequently involves coping with new standards and values. In the technical language of psychology, getting along with the members of the society as best as one can, is called adjustment (Bhardwaj \& Sharma, 2021) ${ }^{[3]}$. Success of an individual is largely depends upon the way which he/she interact with other individuals of the society. Actually education helps individual to cope /adjust with the needs and demands of the society. The ultimate aim of education is to bring about socially acceptable thinking and well desired response to the society. The agencies of Education are mere responsible to mould the behavior and guide in the right direction for becoming a good human being. Social adjustment is not an inborn quality of human being. Environment plays a vital role in the process of conversion from maladjusted to adjusted one (Jain \& Jadav, 2018) ${ }^{[7]}$.

Odisha occupies a unique position among the Indian States and Union Territories for having a rich and colorful tribal scenario (G. Kumar et al., 2021) ${ }^{[8]}$. Majority of Scheduled Tribes live in hilly and forest regions. Their economy is largely subsistence oriented, non-stratified and nonspecialized. Their social system is simple and aspirations and needs are not many. Though the Scheduled Tribes in Odisha have suffered from social, educational and economic backwardness due to geo-historical reasons, they have their own distinctiveness and social-cultural milieu. The process of socio-economic development is going on after independence and has picked up momentum. 62 Scheduled Tribes in Odisha speak as many as 74 dialects. Their ethos, ideology, worldview, value orientations and cultural heritage are rich and varied. At one end of the scale there are nomadic food gatherers and hunters and at the other end, skilled settled agriculturists and horticulturists. The tribal areas of Odisha, therefore, present an extremely diverse socio-economic panorama.

Out of the total tribal population of 70, 32,214 in Odisha, women constitute $3,519323(50.05 \%)$ whose contribution to the state's socio-economic development in very vital. As per census data the ST women constitute only 23.36 percent of main workers as against 57.94 percent male main workers. The percentage of female marginal workers is $17.54 \%$ as against $1.46 \%$, male marginal workers. $59.15 \%$ tribal women are engaged as agricultural laborer's as against $30.27 \%$ of males $.2 .49 \%$ of tribal women are engaged in house hold industries as against $1.14 \%$ ofmale.32.19\%oftribal women work as cultivator as against $60.87 \%$ tribal women contributes $47.92 \%$ to the total man days utilized for the purpose of collection of miner forest produce. Besides household work, the tribal women perform a major part of agricultural operations like breaking clods of earth, weeding, Transplanting, harvesting, threshing and winnowing. Besides, women do most of the work of carrying for the diary animals and marketing of their products so also perform other small industries work too. So, in the domain of socio-economic front, the tribal women play a two-front role-a domestic and economic front.

\section{Review of related Studies}

Ogunsola (2020) ${ }^{[9]}$ studied Parental Socio-Economic Status and Social Adjustment of Students with Learning
Disabilities in Oyo. The results showed that the parental socioeconomic status has positive influence on social adjustment of students with learning disabilities.

Ghatak (2018) ${ }^{[4]}$ studied social adjustment of adolescents. The finding of the study revealed that a significance difference was found in social adjustment between Male and Female adolescents and not significant difference was found in social adjustment between Urban and Rural adolescents. Jain \& Jadav (2018) [7] studied comparative study of adjustment of tribal adolescents of Eklavya model residential schools of Madhya Pradesh boys and girls. This study found that there is significant difference in social adjustment among male and female tribal adolescent students of Eklavya Model Residential Schools of Madhya Pradesh.

Prasad and Kumar (2017) [10] studied on relationship between socio-economic status and social adjustment among dyslexic students. Result indicated that their socio economic status having relationship with the social adjustment of dyslexic students.

Packiaselvi (2017) ${ }^{[11]}$ studied on social adjustment among higher secondary school students and its impact on their academic achievement in Coimbatore district. The result concluded from the study that there is no substantial change with respect to mother tongue, gender, location of school, type of family, educational qualification of parents, occupation of parents, monthly income of parents in their mean score of social adjustment and academic achievement. Sahoo (2017) ${ }^{[12]}$ studied Socio-Economic Development of Tribal in Odisha -An Inter-District Analysis. The study shows that a very high percentage of tribal population still lives below the poverty line in Odisha with a very high Infant Mortality Rate and low literacy rate especially among women.

Bhagat (2016) ${ }^{[2]}$ studied social-adjustment of secondary school students in relation to their gender, academic achievement and parent-child relationship. The results of the study showed that boys are found socially more adjusted than their counterparts. Social-adjustment is found independent of academic-achievement and parent-child relationship.

\section{Rationale}

Different research studies revealed that parental socioeconomic status is a contributing factor towards the social adjustment of tribal children. A proper social adjustment of tribal girls is inevitable to be successful in their social life. Success of an individual is largely depends upon the way which he/she interact with other individuals of the society. Individual success is largely influences National Development. Tribal Girls face difficulty to cope with very different circumstances in their social context due to socioeconomic diversity found among tribal. Under Aspirational Districts programme, NITI Aayog, Govt. of India aims to quickly and effectively transform 112 most under-developed districts across the country. The Aspirational Districts Programme essentially is aimed at localizing Sustainable Development Goals, leading to the progress of the nation (Aspirational Districts Programme | NITI Aayog, 2021) ${ }^{[1]}$. To the knowledge of the researcher there are few studies has been conducted to find the influence of socioeconomic status on social adjustment of tribal girls. This study was an attempt to find out the social adjustment of tribal girls of aspirational districts of Odisha in relation to their socioeconomic status. 


\section{Statement of the Problem}

The study was undertaken to focus on the adjustment problem related with the socioeconomic status of tribal girls. Hence the researcher intended to take upa piece of study on "Social Adjustment of Tribal Girls of Aspirational Districts of Odisha in Relation to Their Socio-economic Status."

\section{Objectives}

1. To study the social adjustment of tribal girls of aspirational districts of Odisha

2. To compare the social adjustment of tribal girls in relation to the locality.

3. To study the socio-economic status of the Parents of the tribal girls of aspirational districts of Odisha

4. To compare the mean score of social adjustment of tribal girls of low, medium and high Parental socioeconomic status.

5. To find the relationship between social adjustment of adolescent tribal girls and their Parent's socio-economic status

\section{Hypotheses}

$\mathrm{H}_{0} 1$ : There is no significant difference between social adjustment of adolescent tribal students of urban and rural locality.

$\mathrm{H}_{0}$ 2: There is no significant difference between mean score of social adjustment of tribal girls of low, medium and high Parental socio-economic status

$\mathrm{H}_{0} 3$ : There is no significant relationship between social adjustment of adolescent tribal girls and their Parent's socioeconomic status.

\section{Methodology}

For achieving objectives, investigator adopted descriptive survey method for the present study. Survey study may be described as the one which uses quantitative methods to describe and discover quantifiable relationships between existing variables. In the present study it was intended to study Social Adjustment of Adolescent Tribal Girls in Relation to Their Socio-economic Status.

\section{Population and Sampling}

All secondary school students of aspirational districts of Odisha was considered as Population of the study. So, all the students of secondary school, studying in class IX and X in the Malkangiri, Nuapada, Balangir, Kalahandi, Kandhamal, Gajapati, Dhenkanal, Koraput, Rayagada, Nawarangapur district are population for the Present study. From above mentioned population researcher randomly selected 316 tribal girls as the sample of the study.

\section{Tool}

According to the nature and specificity of the present study, the researcher was able to find relevant standardized tools to study the Social Adjustment of Adolescent Tribal Girls in Aspirational Districts. Social Adjustment Scale by Dr. Ashutosh Kumar has been adopted for data collection of the study. There are 16 items in the tool. Investigator standardized the tool with respect to the sample of his study. The tool has been given to the experts to establish the content validity. Reliability of the tool was established by split half method. The reliability of the tool is 0.76 . Hence, the tool is reliable. Socio-economic status scale developed and standardized by Rajeev Lochan Bharadwaj, translated \& standardized by Dr Amulya Kumar Acharya adopted for data collection of the study. There are 42items in the tool. Investigator standardized the tool with respect to the sample of his study. The tool has been given to the experts to establish the content validity. Reliability of the tool was established by split half method. The reliability of the tool is 0.76 , which is reliable.

\section{Analysis and Interpretation}

The tabulated data have no meaning unless they are analyzed and interpreted by statistical technique so as to arrive at significant conclusions. However valid, reliable and adequate the data may be, these do not serve any worthwhile purpose unless they are systematically classified and tabulated, scientifically analyzed intellectually interpreted and rationally concluded. Therefore, after the data have been collected, the investigator processed and analyzed the data to draw proper inferences. The analysis and interpretation of the data as per the objectives are as follows.

Objective-1: To study the social adjustment of tribal girls of aspirational districts of Odisha.

Table 1: Level of social adjustment of tribal girls of aspirational districts of Odisha.

\begin{tabular}{|c|c|c|c|c|c|}
\hline Sl. No. & Ranges of z- Score & Grade & Level of social adjustment & No. of tribal girls in this range & \% \\
\hline 1. & $+2.10 \&$ Above & A & Extremely High & 20 & 2.8 \\
\hline 2. & +1.26 to +2.00 & B & High & 83 & 6.3 \\
\hline 3. & +0.51 to +1.25 & C & Above average & 98 & 26.2 \\
\hline 4. & +0.50 to -0.50 & D & Average & 69 & 31.01 \\
\hline 5. & -0.51 to -1.30 & E & Below average & 25 & 22.25 \\
\hline 6. & -1.29 to -2.00 & F & Low & 12 & 8.06 \\
\hline 7. & $-2.00 \&$ above & G & Extremely Low & 3.7 \\
\hline
\end{tabular}




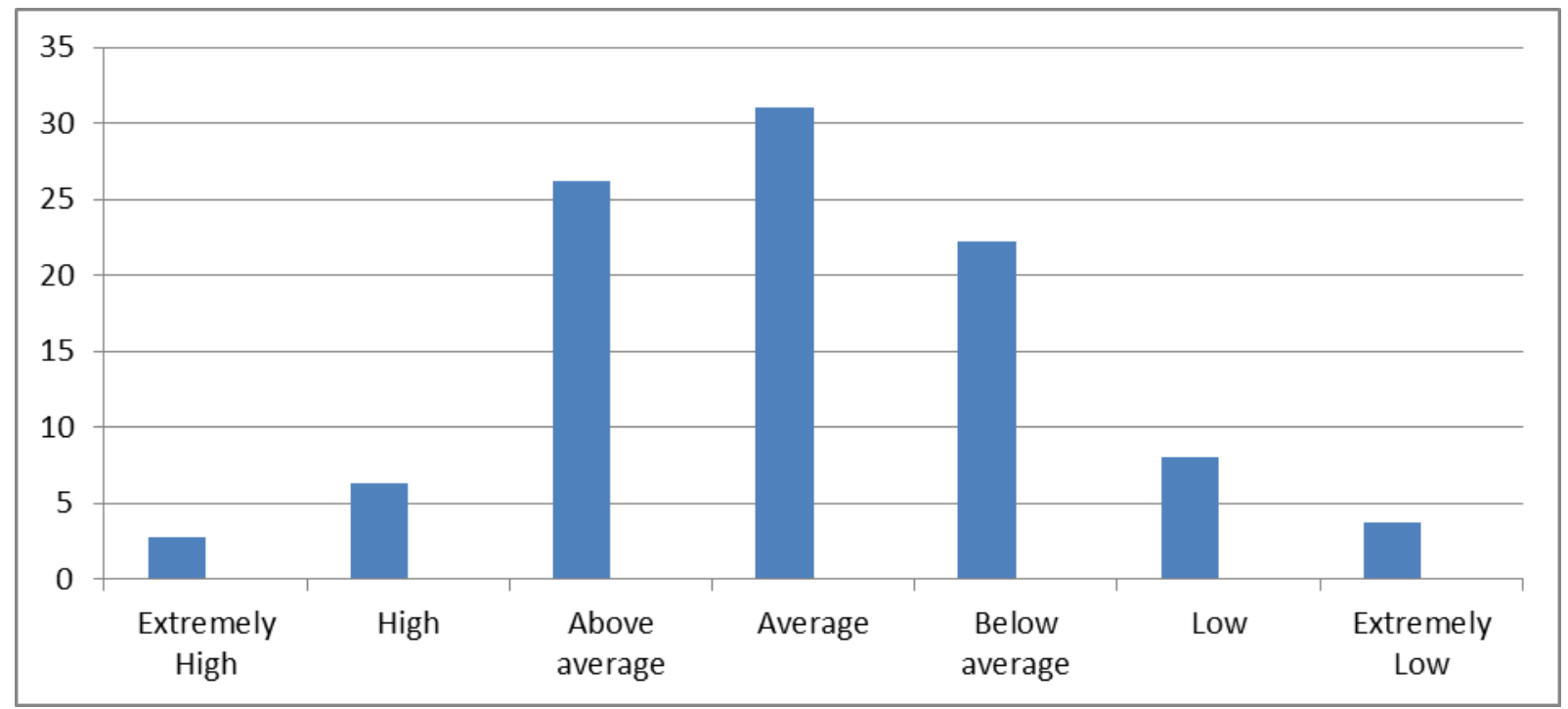

Fig 1: Level of social adjustment of tribal girls of aspirational districts of Odisha.

From the above table it is found that a majority $31.01 \%$ of tribal girls have average level of social adjustment. About $26.2 \%$ tribal girls have above average level of social adjustment. About $6.3 \%$ and $2.8 \%$ tribal girls have high and extremely high level of social adjustment respectively. In contrary $22.25 \%$ and $8.06 \%$ tribal girls have below average and low level of social adjustment respectively. Whereas,
$3.7 \%$ tribal girls have extremely low level of social adjustment.

Objective 2: To compare the social adjustment of tribal girls in relation to the locality

Hypothesis $\left(\mathrm{H}_{0}\right)$ : There is no significant difference between social adjustment rural and urban tribal girls.

Table 2: Locality wise M, SD, N, and t-value of rural and urban tribal girls of their social adjustment

\begin{tabular}{|c|c|c|c|c|c|}
\hline Locality & M & SD & N & t-value & Remark \\
\cline { 1 - 4 } Urban & 119.49 & 18.41 & 168 & \multirow{2}{*}{1.816} & \multirow{2}{*}{ Not significant } \\
\hline Rural & 116.68 & 12.66 & 148 & & \\
\hline
\end{tabular}

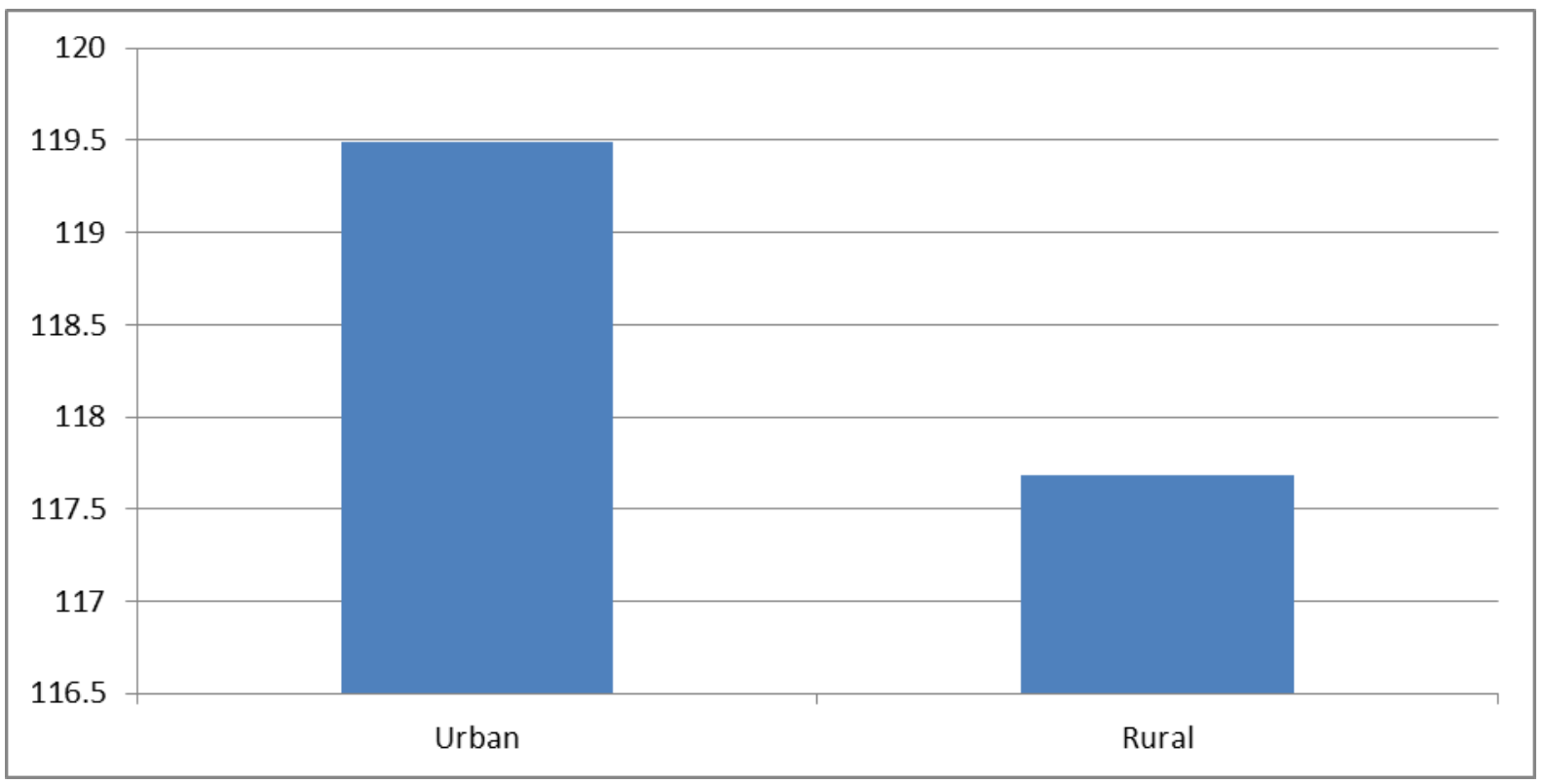

Fig 2: Level of social adjustment rural and urban tribal girls.

From the above table it is evident that the $\mathrm{t}$-value is 1.816 which is not significant. It shows that mean score of social adjustment of urban and rural tribal girls did not differ significantly. Thus the null hypothesis that there is no significant difference between social adjustment of urban and rural tribal girls is not rejected. It means urban tribal girls have better social adjustment that rural tribal girl. Objective 3. To study the socio-economic status of the Parent's of the tribal girls of aspirational districts of Odisha. 
Table 3: Given below shows the Level of Socio-Economic status of the Parent's of the tribal girls of aspirational districts of Odisha

\begin{tabular}{|c|c|c|c|c|}
\hline Sl. No. & Range of Scores & Level of Socio-Economic Status & No of Parent's of the tribal girls & Percentage \\
\hline 1. & $151 \&$ Above & High & 66 & 20.88 \\
\hline 2. & $130-150$ & Average & 71 & 22.46 \\
\hline 3. & $129 \&$ Below & Low & 179 & 56.64 \\
\hline
\end{tabular}

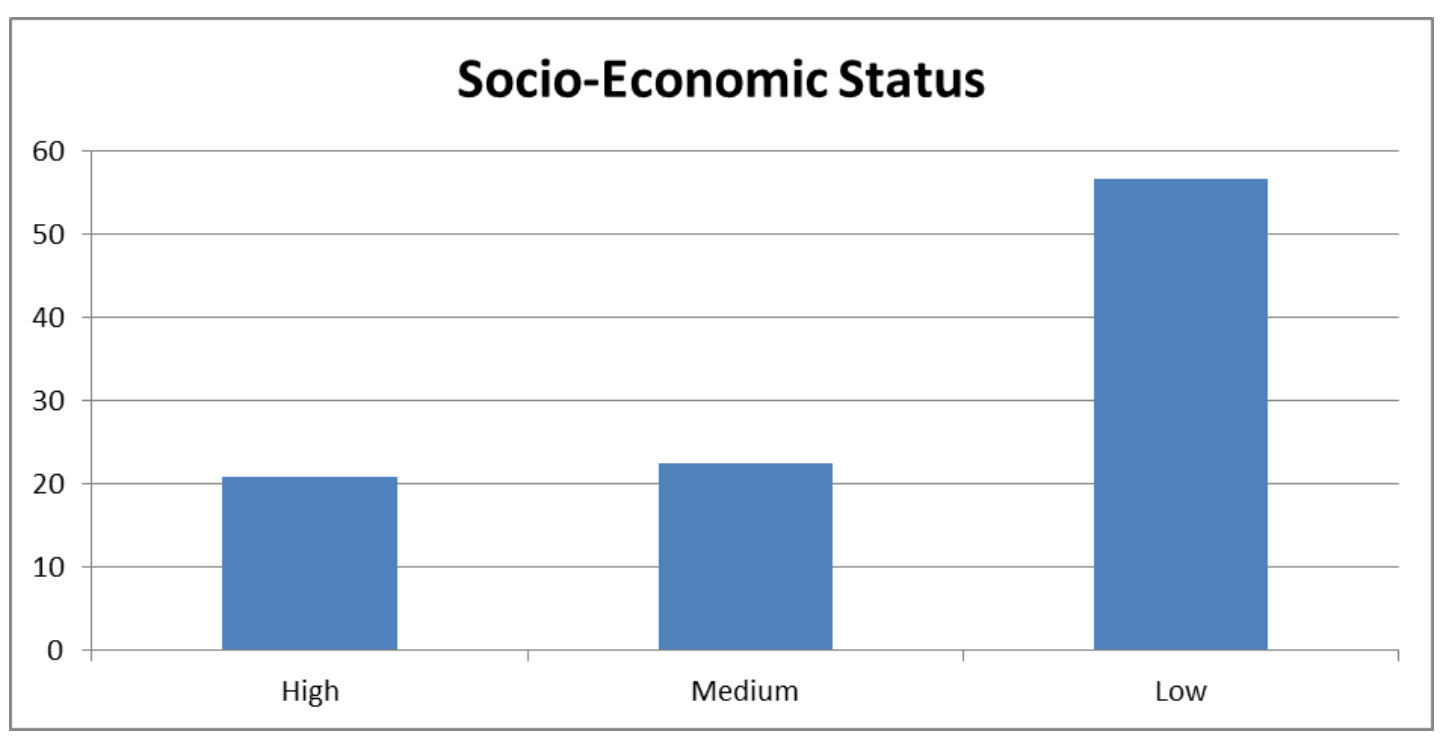

Fig 3: Level of Socio-Economic status of the Parent's of the tribal girls of aspirational districts of Odisha

From the above table it is evident that $56.64 \%$ of parent's of the tribal girls of aspirational districts have low socioeconomic status. $22.46 \%$ of Parent's of the tribal girls of aspirational districts have medium socio-economic status where as $20.88 \%$ of the Parent's of tribal girls of aspirational districts have High socio-economic status.
Objective 4: To compare the mean score of social adjustment of tribal girls of low, medium and high Parental socio-economic status.

Hypothesis $\left(\mathrm{H}_{0}\right)$ : There is no significant difference between mean score of social adjustment of tribal girls of low, medium and high Parental socio-economic status

Table 4: Level of social adjustment of tribal girls of low, medium and high Parental socio-economic status

\begin{tabular}{|c|c|c|c|c|c|}
\hline Sources of Variance & Sum of Square & df & Mean Sum of Square & F value & Remark \\
\hline Between Groups & 1386.4 & 2 & 693.2 & \multirow{2}{*}{146.86} & \multirow{2}{*}{ Significant $p<0.05$} \\
\hline Within Groups & 1479.7 & 313 & 4.72 & & \\
\hline
\end{tabular}

From table 4 , it can be seen that the f-value is 146.86 which is significant. It indicates that the mean score of social adjustment of tribal girls belonging to high, medium and low socio-economic status differs significantly. Thus the null hypothesis that there is no significant difference between mean score of social adjustment of tribal girls of low, medium and high Parental socio-economic status is rejected.

Objective: To find the relationship between social adjustment of adolescent tribal girls and their Parent's socioeconomic status

Hypothesis $\left(\mathrm{H}_{0}\right)$ : There is no significant relationship between social adjustment of adolescent tribal girls and their Parent's socio-economic status.

Table 5: Correlation coefficient between social adjustment and socio-economic status of the tribal girls of aspirational districts of Odisha

\begin{tabular}{|c|c|c|}
\hline Variables & N & r- value \\
\hline Social Adjustment & \multirow{2}{*}{316} & 0.08 \\
\hline Socio-economic status & & \\
\hline
\end{tabular}

From the Table 5 it is evident that the coefficient of correlation between social adjustment and socio-economic status is 0.08 which is positive and significant at 0.05 level with $\mathrm{df}=316$. It shows that social adjustment and socio- economic status were positive and significantly correlated. Thus, the null hypothesis is rejected.

\section{Major Findings}

- Majority of tribal girls have average level of social adjustment.

- Social adjustment of urban and rural tribal girls did not differ significantly.

- Majority of parent's of the tribal girls of aspirational districts have low socio-economic status.

- Social adjustment of tribal girls belonging to high, medium and low socio-economic status differs significantly.

- Social adjustment and socio-economic status were positive and significantly correlated.

\section{Conclusion}

The Government of India has taken initiatives to transform aspirational district with a vision of new India to improve India's ranking in Human Development Index by raising the standards of life of citizen and ensuring inclusive growth for all. But practically it has been observed from the findings of various research studies on tribal girls have poor social and emotional adjustment compared to non-tribal in the aspirational districts of Odisha. Social adjustment is considered as one of the important characteristics of 
adolescent girls for harmonious growth and responsible citizens in the society. As most of the learning occurs in social context, adolescent tribal girl's social adjustment matters to cope in school atmosphere, solving the academic issues, minimizing boredom in class and drop out. There are various factors which influences the social adjustment of tribal girls like socio-economic status of parents, teachers personality and democratic attitude, need based curriculum, adequate recreational facilities, classroom climate, cordial and congenial relationship with the parents. The findings of the present study depicted the influences of socio-economic status on social adjustment of tribal girl students only in aspirational districts of Odisha. As school is most important factors for socialization of a child, so influence of school atmosphere may be taken up for understanding the tribal adolescent girls social adjustment which will be useful for the policy makers and stakeholders.

\section{References}

1. Aspirational Districts Programme | NITI Aayog. 2021. https://www.niti.gov.in/aspirational-districtsprogramme.

2. Bhagat P. Social-adjustment of Secondary school students in relation to their Gender. Academic achievement and Parent-child relationship. Int. J. of $A d v$. Res. 2016;4:64-71. http://www.journalijar.com/article/10480/socialadjustment-of-secondary-school-students-in-relation-totheir-gender,-academic-achievement-and-parent-childrelationship/

3. Bhardwaj S, Sharma U. A Comparitive Study of Social Intelligence, Emotional Intelligence and Adjustment among College Students, 2021.

4. Ghatak R. A study on social adjustment of adolescents. International Journal of Scientific Development and Research. 2018;3(8):207-210. https://www.ijsdr.org/papers/IJSDR1808034.pdf

5. Goodstein LD, Lanyon RI. Adjustment, behavior, and personality. Addison Wesley Publishing Company, 1975.

6. Jain S, Yadav K. Comparative Study of Emotional Intelligence of Tribal Adolescents of Eklavya Model Residential Schools of Madhya Pradesh boys and girls. International Journal of Research in Social Sciences. 2019;9(1):109-122.

7. Jain S, Yadav K. Comparative Study of Adjustment of Tribal Adolescents of Eklavya Model Residential Schools of Madhya Pradesh Boys and Girls. International Research Journal of Management Sociology \& Humanities. 2018;9(10):64-74. https://doi.org/10.32804/IRJMSH

8. Kumar G, Rai S, Jalaluddin M, Tripathi RM, Bagchi A, Tiwari R. Assessment of oral health status and treatment needs amongst the tribals residing in Northern Bhubaneswar, Odisha. Journal of Family Medicine and Primary Care. 2021;10(8):3051.

9. Ogunsola GO. Parental Socio-Economic Status and Social Adjustment of Students with Learning Disabilities in Oyo. Hybrid Journal of Psychology. 2020;1(1). $\quad$ Retrieved from https://royalliteglobal.com/psychology/article/view/360

10. Prasad SK, Kumar A. A study on relationship between socio-economic status and social adjustment among dyslexic students. Indian Journal of Health and
Wellbeing.

2017;8(7):660-664. https://www.proquest.com/docview/1961778248?pqorigsite $=$ gscholar $\&$ fromopenview $=$ true

11. Packiaselvi P, VA M. A Study on Social Adjustment Among Higher Secondary School Students And Its Impact on Their Academic Achievement In Coimbatore District. International Journal of Research Granthaalayah, 2017;5(6):458-463.

https://doi.org/10.29121/granthaalayah.v5.i6.2017.2056

12. Sahoo M. Socio-Economic Development of Tribal in Odisha -An Inter-District Analysis. DeshVikas, 2017;4(3):02-12.

https://www.researchgate.net/publication/333943834_S ocio-

economic_Development_of_tribal_in_Odisha_An_inter $-$

district_analysis\#: :text=The\%20study $\% 20$ also $\% 20 \mathrm{hig}$ hlights $\% 20$ the,condition $\% 20$ of $\% 20$ tribal\%20in\%20Indi a.\&text=The $\% 20$ study $\% 20$ shows $\% 20$ that $\% 20$ a,literacy $\% 20$ rate\%20especially\%20among\%20women.

13. Shaffer LS. In Boring Longfield, 1961.

14. http://www.scstrti.in/index.php/communities/tribes\#: :t ext=Majority\%20of\%20Scheduled\%20Tribes\%20live,a nd\%20needs $\% 20$ are $\% 20$ not $\% 20$ many.

15. http://www.atlcodisha.org/index.php?r=tribe/index

16. https://www.niti.gov.in/aspirational-districtsprogramme 